\title{
Fracture load of ceramic crowns supported by some novel anchoring dental systems
}

\author{
Isil Cekic-Nagas, ${ }^{1 *}$ Emre Nagas, ${ }^{2}$ Ferhan Egilmez, ${ }^{1}$ \\ Gulfem Ergun, ${ }^{1}$ Pekka Kalevi Vallittu, ${ }^{3,4}$ \\ Lippo V. Lassila ${ }^{4}$ \\ ${ }^{1}$ Department of Prosthodontics, Faculty of Dentistry, Gazi \\ University, Ankara, ${ }^{2}$ Department of Endodontics, Faculty \\ of Dentistry, Hacettepe University, Ankara, Turkey, ${ }^{3}$ City of \\ Turku, Welfare Division, Turku, ${ }^{4}$ Department of Biomaterials \\ Science and Turku Clinical Biomaterials Centre-TCBC, \\ Institute of Dentistry, University of Turku, Turku, Finland
}

\begin{abstract}
OBJECTIVE: This study aimed to evaluate the fracture load of endocrown restorations and fiber-reinforced composites (FRCs) fabricated through computer-aided design/ computer-aided manufacturing (CAD-CAM) for postcores of anterior teeth.

Materials and Method: Forty post-core-supported crowns and endocrowns were fabricated through CAD-CAM on a canine root zirconia model (Ice Zirconia, ZirkonZahn GmBH, Bruneck, Italy). The static load-bearing capacity was measured on the following restoration groups: Group 1: zirconia crown (Prettau anterior, ZirkonZahn GmBH) retained with CAD-CAM one-piece FRC post-core crown system (experimental CAD-CAM FRC block); Group 2: zirconia crown (Prettau anterior) retained with FRC post (GC Corp., Tokyo, Japan) with discontinuous fiber composite (EverX posterior, GC Corp) core; Group 3: zirconia endocrown (Prettau anterior); and Group 4: lithium disilicate ceramic endocrown (IPS e.max CAD, Ivoclar Vivadent AG, Schaan, Liechtenstein) ( $n=10 /$ per group). After the adhesive cementation of crowns/endocrowns to the zirconia root model, a load was applied at $45^{\circ}$ to the long axis of the teeth and measured using a universal testing machine. The fracture modes were visually examined. The statistical analyses were performed using one-way ANOVA and Tukey post-hoc tests $(p<0.05)$.
\end{abstract}

RESULTS: The fracture load significantly differed among the groups $(p<0.05)$ and was ranked as follows: Group 3 $(1168 \pm 141 N)>$ Group $4(721 \pm 96 N) \geq$ Group $1(680 \pm 86$ N) > Group $2(534 \pm 36$ N).

CONCLUSION: Endocrown monoblock restorations can

Received: July 11, 2017; Accepted: October 9, 2017

*Corresponding author: Dr. Isil Cekic-Nagas, Gazi University, Faculty of

Dentistry, Department of Prosthodontics, Bişkek Cad. (8. Cad.), 82. Sk., No: 4

06510, Emek, Ankara, Turkey;

E-mail: isilcekic@gmail.com be used as an alternative to fiber-reinforced post-core supported crown restorations.

KEYwORDS: Ceramics; computer-aided design; computeraided manufacturing; post and core technique

Citation: Cekic-Nagas I, Nagas E, Egilmez F, Ergun G, Vallittu PK, Lassila LV. Fracture load of ceramic crowns supported by some novel anchoring dental systems. Acta Odontol Turc 2018;35(2):33-7

Edıтor: Güven Kayaoğlu, Gazi University, Ankara, Turkey

Copyright: @ 2018 Cekic-Nagas et al. This work is licensed under a Creative Commons Attribution License. Unrestricted use, distribution and reproduction in any medium is permitted provided the original author and source are credited.

FundiNG: None declared.

Conflict of Interest: The author Pekka K. Vallittu consults 'Stick Tech-member of GC' in training, research and development. The other authors declare no conflict of interest related to this study.

\section{INTRODUCTION}

With the development of adhesive technology fabricated through computer-aided design/computer-aided manufacturing (CAD/CAM) technique, the demand for long-term machinable materials has significantly increased; these materials include lithium disilicate glass ceramics, leucite-reinforced glass ceramics, feldspathic glass ceramics, aluminum oxide, and yttrium tetragonal zirconia polycrystals. ${ }^{1,2}$ Lithium disilicate glass-ceramic (IPS e.max CAD, Ivoclar Vivadent AG, Schaan, Liechtenstein) could be used in monolithic (fully anatomical) restorations due to its favorable translucency and shade variety. This material could also be used to produce the core part through veneering with veneering ceramics. ${ }^{3-6}$ Moreover, monolithic zirconia restorations have been increasingly used in restorative dentistry to eliminate the risk of veneer chipping or fracture of zirconia veneering ceramics. ${ }^{7}$ To improve the optical properties of monolithic zirconia, manufacturers add cubic zirconia for diminishing the opacity of yttria-stabilized tetragonal zirconia polycrystals and increasing the yttria content from 6\% to 8\%.8,9 Prettau Anterior (Zirkonzahn, Bruneck, Italy) is a fully stabilized zirconia ceramic, with yttria concentration as low as $12 \%$ to achieve full stabilization. ${ }^{10}$ 


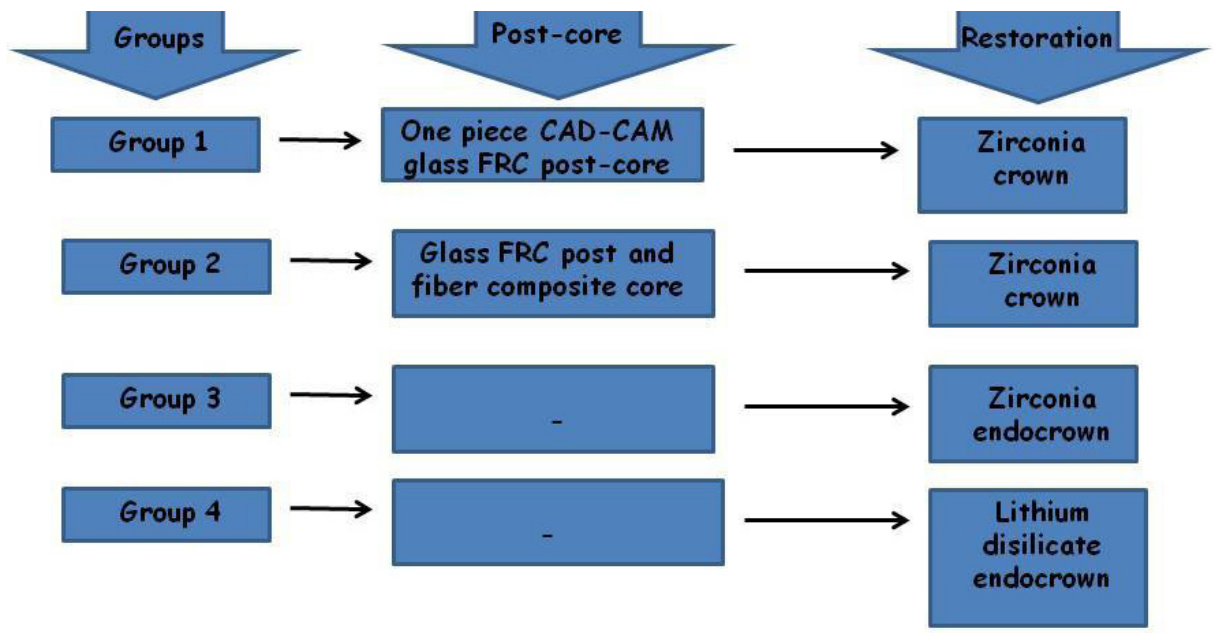

Figure 1. Experimental groups according to restoration

Endodontically-treated teeth are generally restored with prefabricated or cast metal posts and cores and with prefabricated and custom fiber-reinforced composite (FRC) posts. ${ }^{11,12}$ With the advent of CAD-CAM technology, endocrowns and one-piece CAD-CAM post-cores are considered treatment alternatives. ${ }^{13} \mathrm{~A}$ previous study fabricated one-piece fiber-reinforced composite (FRC) posts and cores through CAD-CAM and used them to provide good adaptation in the post space and crown supports and to decrease the chair time needed. ${ }^{12}$ Furthermore, as another benefit of endocrowns, monoblock restoration achieved by combining the intraradicular post, the core, and the crown in one component can reduce number of adhesive interfaces that are prone for debonding..$^{11,13,14}$

To the authors' knowledge, few works in literature have compared the fracture load of crowns (monolithic ceramic endocrown restorations; IPS e.max CAD and Prettau anterior) and crowns with retained one-piece CAD-CAM FRC post-core or combination of regular fiber post and discontinuous FRC core.

This study aims to compare fracture load and fracture mode of anterior crown systems of these kinds. The null hypothesis states that the type of restoration would not affect the fracture load of the restorations.

\section{Materials and Method Specimen preparation}

Identically shaped post-core supported crowns and endocrowns were fabricated on a canine root zirconia model (Ice Zirconia, ZirkonZahn GmBH, Bruneck, Italy). The root was embedded in autopolymerizing acrylic resin (Palapress, Vario; Heraeus Kulzer, Wehrheim, Germany) by using a cylindrical plastic mold $(20 \mathrm{~mm}$ in height and $20 \mathrm{~mm}$ in diameter). Figure 1 shows the experimental groups categorized according to the restoration performed. The specimens were divided into four groups as follows ( $n=10 /$ per group):

Group 1: Zirconia crown (7.6 $\mathrm{mm}$ in length) (Prettau anterior, ZirkonZahn $\mathrm{GmBH}$ ) retained with one-piece continuous unidirectional CAD-CAM glass FRC postcore (14.6 mm in length),

Group 2: Zirconia crown (Prettau anterior) $(7.6 \mathrm{~mm}$ in length) retained with regular glass $F R C$ post $(1.6 \mathrm{~mm}$ in diameter; GC Corp., Tokyo, Japan) with discontinuous fiber composite core (14.6 mm in length; EverX posterior, GC Corp.),

Group 3: Zirconia endocrown (12.6 mm in length; Prettau anterior, ZirkonZahn GmBH),

Group 4: Lithium disilicate ceramic endocrown (12.6 $\mathrm{mm}$ in length; IPS e.max CAD Ivoclar Vivadent, Schaan, Liechtenstein).

The dimensions of the specimens in each group are shown in Figure 2. In Group 1, one-piece continuous unidirectional CAD-CAM glass FRC post-core was prepared through CAD-CAM by using an experimental FRC block. In Group 2, the fiber composite core (EverX posterior) was prepared using silicone mold (transparent polyvinylsiloxane template; Memosil 2, HeraeusKulzer, Hanau, Germany) and CAD-CAM milled fiber post-core (that was used in Group 1) to standardize
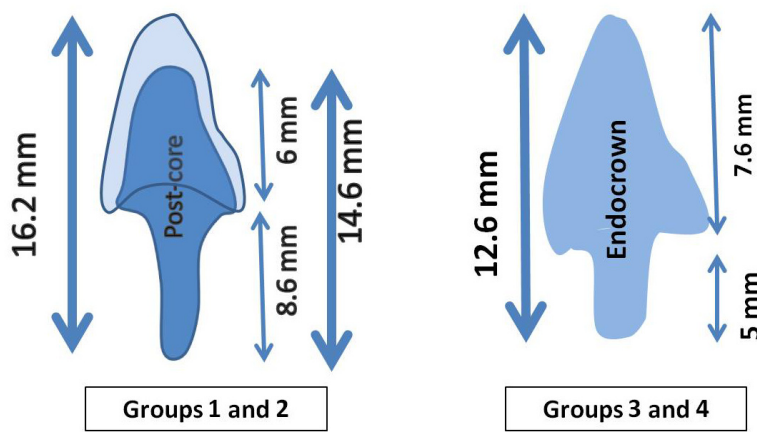

Figure 2. Dimensions of the restorative materials in groups; Group 1: Zirconia crown retained with one-piece CAD-CAM glass FRC post-core, Group 2: Zirconia crown retained with regular glass FRC post with discontinuous fiber composite core, Group 3: Zirconia endocrown, Group 4: Lithium-disilicate ceramic endocrown 


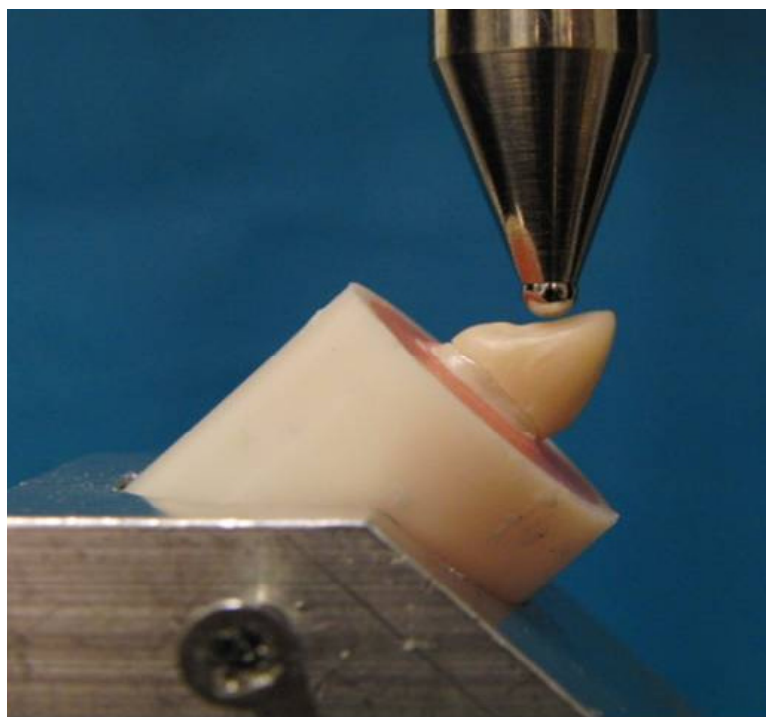

Figure 3. Fracture load test set-up

the core dimensions In Groups 1 and 2, the posts were ultrasonically cleaned for 2 min and silanized (GC Ceramic Primer, GC Corp.) for $60 \mathrm{~s}$.

For the standardization of applied force during the fracture load test, zirconia crowns (Prettau anterior) of Groups 1 and 2 were fabricated to have the same dimensions as those of endocrowns of Groups 3 and 4. Impressions of the cores were made with a polyvinylsiloxane material (Aquasil Ultra LV; Dentsply DeTrey $\mathrm{GmbH}$, Konstanz, Germany). Crowns were fabricated using CAD-CAM.

In groups 3 and 4, endocrowns (Prettau anterior and IPS e.max CAD) were produced by CAD-CAM. The endocrowns were grit blasted with aluminum oxide particles (Rocatec Pre, 3M ESPE, St. Paul, MN, USA) of $110 \mu \mathrm{m}$ diameter at a distance of $1 \mathrm{~cm}$ at $280 \mathrm{kPa}$ for $5 \mathrm{~s}$ and silanized for $60 \mathrm{~s}$ (GC Ceramic Primer).

Before each cementation procedure, the root model was also grit blasted (Rocatec Pre). All post-cores, crowns, and endocrowns were cemented with a selfadhesive luting agent (Clearfil SA Cement, Kuraray Medical Co., Osaka, Japan) and light cured with a LED light-curing unit (Elipar S10, 3M ESPE) for $20 \mathrm{~s}$ for each side. After cementation, the specimens were stored for $15 \mathrm{~min}$ at room temperature until testing.

\section{Fracture load test}

Load was applied on the palatal surface by using a testing machine (Lloyd LRX, Lloyd Instruments, Fareham Hants, UK) at $45^{\circ}$ under crosshead speed of $0.5 \mathrm{~mm} / \mathrm{min}$ until a fracture occurred (Figure 3). Force was recorded using corresponding software (Lloyd Nexygen, Lloyd Instruments).

Failure modes were observed with an optical microscope at $\times 40$ magnification (Stereomicroscope, Wild M3B, Heerbrugg, Switzerland).

\section{Statistical analysis}

Descriptive data were calculated, and the normality of data distribution was tested using Shapiro-Wilk test. The data were analyzed using one-way ANOVA and Tukey post-hoc tests ( $p$ < 0.05) (SPSS 15.0, SPSS Inc., Chicago, IL, USA).

\section{Results}

\section{Fracture load}

The mean values, standard deviations, and differences of fracture load in all of the groups are presented in Figure 4. One-way ANOVA revealed significant differences in the fracture load values between postcore and endocrowns $(p<0.05)$. The mean fracture load values are ranked as follows: group 3 (1168 \pm 141 $\mathrm{N})>\operatorname{group} 4(721 \pm 96 \mathrm{~N}) \geq \operatorname{group} 1(680 \pm 86 \mathrm{~N})>$ group $2(534 \pm 36 \mathrm{~N})$. The highest and lowest fracture load values were obtained in group $3(1441 \mathrm{~N})$ and group $2(395.5 \mathrm{~N})$, respectively. Moreover, the mean fracture load was not significantly different between groups 1 and 4.

\section{Fracture mode}

During the fracture load test, two endocrown (Prettau anterior) specimens were debonded (between cement and root) and re-tested. In groups 3 and 4, all of the failures recorded included endocrown/crown fracture from 1-2 $\mathrm{mm}$ below the cervical margin (\%100). In group $1,70 \%$ of the fractures were post fracture (1-2 $\mathrm{mm}$ below the cervical margin). In group 2, the cores mostly detached from the post ( $80 \%$; Table 1$)$.

\section{Discussion}

Numerous tests are available for evaluating the mechanical properties of posts and $\operatorname{cores}^{15-18}$. In the present study, static fracture load test was performed to compare the mechanical stability of endocrowns and post-cores.

According to the results of this study, monolithic ceramic endocrowns demonstrated greater fracture load values than FRC post-cores; as such, the hypothesis was rejected. Chang et al. ${ }^{14}$ compared the fracture resistance and failure modes of endo-crowns

Table 1. The percentage of fracture modes of the specimens

\begin{tabular}{cccc}
\hline Groups & $\begin{array}{c}\text { Endocrown/crown } \\
\text { fracture }\end{array}$ & $\begin{array}{c}\text { Post } \\
\text { fracture }\end{array}$ & $\begin{array}{c}\text { Core } \\
\text { detachment }\end{array}$ \\
\hline $\mathbf{1}$ & 0 & 70 & 30 \\
$\mathbf{2}$ & 0 & 20 & 80 \\
$\mathbf{3}$ & 100 & $\mathrm{~N} / \mathrm{A}$ & $\mathrm{N} / \mathrm{A}$ \\
\hline
\end{tabular}

Group 1: Zirconia crown retained with one-piece CAD-CAM glass FRC postcore, Group 2: Zirconia crown retained with regular glass FRC post with discontinuous fiber composite core, Group 3: Zirconia endocrown, Group 4: Lithium-disilicate ceramic endocrown. N/A: Not applicable 


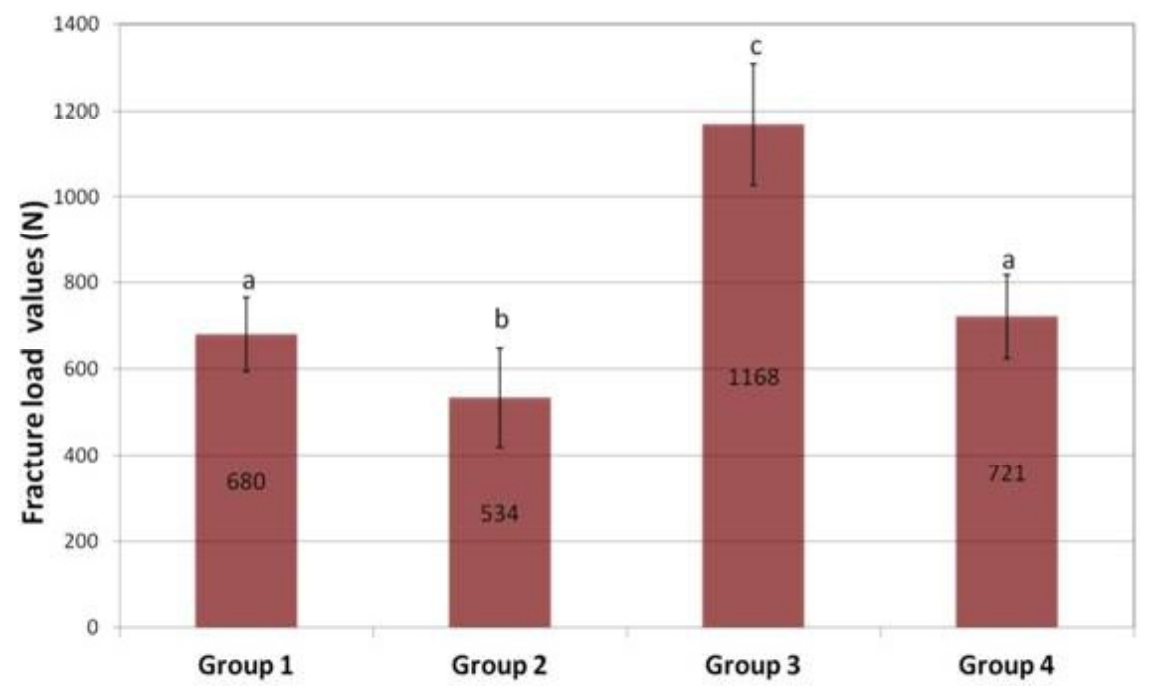

Figure 4. Fracture load values of the tested groups (mean and standard deviation); different lowercase letters indicate statistically significant differences $(p<0.05)$. Group 1: Zirconia crown retained with one-piece CAD-CAM glass FRC post-core, Group 2: Zirconia crown retained with regular glass FRC post with discontinuous fiber composite core, Group 3: Zirconia endocrown, Group 4: Lithium-disilicate ceramic endocrown.

with classically designed crown supported with glass FRC posts and composite cores; this study concluded that ceramic endo-crown (ProCAD leucite-reinforced ceramic blocks, Ivoclar Vivadent Ag) groups showed significantly higher fracture resistance than classic fiberreinforced and designed groups. In the present study, groups 3 and 4 supported by endocrowns restorations demonstrated higher fracture load values than FRC groups (groups 1 and 2).

A previous in vitro study indicated that monolithic zirconia crowns exhibited higher fracture load than monolithic lithium disilicate, layered zirconia, or metal crowns. ${ }^{19}$ In the present study, monolithic zirconia endocrown (group 3) demonstrated higher mean fracture load $(1168 \pm 141 \mathrm{~N})$ than monolithic lithium disilicate endocrown $(721 \pm 96 \mathrm{~N}$; group 4). The observed fracture load values $(534 \mathrm{~N}-1168 \mathrm{~N})$ obtained at the time of fracture under loading were higher than the mean masticatory forces in the anterior region $(325 \mathrm{~N} \pm 116 \mathrm{~N}$ and $382 \pm 133 \mathrm{~N}$ for females and males, respectively). ${ }^{20,21}$ Therefore, none of the tested restoration groups could be considered at risk for failure due to normal occlusal forces.

Based on the fracture analysis in the present study, given that the fracture mostly occurred in the material (post/endocrown) (unfavorable fracture mode); the differences in fracture values among groups 1,3 , and 4 could be related to the strength of the material itself. The detachment of the core from the post (mostly seen in Group 2) might be a clinically more favorable failure mode than the fracture of the post or endocrown. The elasticity moduli were $20 \mathrm{GPa}$ for the fiber post, $95 \mathrm{GPa}$ for monolithic lithium disilicate, and $210 \mathrm{GPa}$ for zirconia. Fahmy $^{22}$ reported that high elastic modulus cause high stress concentrations, resulting in root fractures. Therefore, the high elasticity moduli of monolithic lithium disilicate and zirconia tested in the present study might be the cause of catastrophic endocrown fractures for groups 3 and 4 during testing. However, in group 2, the low fracture load values might be attributed to the detachment of the core from the post material.

In this experimental study, the crowns were tested using high-strength zirconia root model. The results supported that this root model was considerably more rigid than a natural root model. The previously reported isoelasticity advantage of FRC post systems with dentin properties was not evident in the present work. The type of material used in the root model should be considered to interpret fracture mode types. Therefore, we assume that the fracture modes would have been more beneficial with FRC systems if the root model material contained dentin.

The design of this in vitro study has several limitations for simulating clinical conditions. First, rigidly mounted zirconia-based abutments were used instead of natural teeth in periodontal ligament simulation. These abutments exhibit lower elastic modulus than natural teeth. Second, aging could be used to understand clinical behavior of bonded bridges. Further studies should be conducted to clarify the effects of thermomechanical loading on tested endocrowns and post-core systems. In addition, clinical long-term studies are crucial for understanding the mechanical behavior and reliability of the tested materials.

\section{ConcLusion}

Within the limitations of this in vitro study, monoblock endocrowns fabricated through CAD-CAM exhibited higher fracture load values than fiber-reinforced postcores. These monoblock endocrowns could be an alternative to post-core retained restorations. 


\section{ACKNOWLEDGEMENTS}

This study belongs to the research activity of Biocity Turku Biomaterials Research Program (www. biomaterials.utu.fi). This study was presented at the 20th International Esthetic Dental Congress in Istanbul, Turkey, on October 21-23, 2016, and was chosen as the best poster presentation by the committee.

\section{REFERENCES}

1. Lauvahutanon S, Takahashi $\mathrm{H}$, Shiozawa M, Iwasaki N, Asakawa $\mathrm{Y}$, Oki M, et al. Mechanical properties of composite resin blocks for CAD/ CAM. Dent Mater J 2014;33:705-10.

2. Elsaka SE. Bond strength of novel CAD/CAM restorative materials to self-adhesive resin cement: the effect of surface treatments. J Adhes Dent 2014;16:531-40

3. Guess PC, Zavanelli RA, Silva NR, Bonfante EA, Coelho PG, Thompson VP. Monolithic CAD/CAM lithium disilicate versus veneered Y-TZP crowns: comparison of failure modes and reliability after fatigue. Int J Prosthodont 2010;23:434-42.

4. Yu W, Guo K, Zhang B, Weng W. Fracture resistance of endodontically treated premolars restored with lithium disilicate CAD/CAM crowns or onlays and luted with two luting agents. Dent Mater J 2014;33:349-54.

5. Magne $\mathrm{P}$, Schlichting LH, Maia HP, Baratieri LN. In vitro fatigue resistance of CAD/CAM composite resin and ceramic posterior occlusal veneers. J Prosthet Dent 2010;104:149-57.

6. Schmitter M, Mueller D, Rues S. Chipping behaviour of all-ceramic crowns with zirconia framework and CAD/CAM manufactured veneer. J Dent 2012;40:154-62.

7. Sulaiman TA, Abdulmajeed AA, Donovan TE, Ritter AV, Lassila LV, Vallittu PK, et al. Degree of conversion of dual-polymerizing cements light polymerized through monolithic zirconia of different thicknesses and types. J Prosthet Dent 2015;114:103-8.

8. Muñoz EM, Longhini D, Antonio SG, Adabo GL. The effects of mechanical and hydrothermal aging on microstructure and biaxial flexural strength of an anterior and a posterior monolithic zirconia. J Dent 2017;63:94-102.

9. Sulaiman TA, Abdulmajeed AA, Shahramian K, Lassila L. Effect of different treatments on the flexural strength of fully versus partially stabilized monolithic zirconia. J Prosthet Dent 2017;118:216-20.

10. Sulaiman TA, Abdulmajeed AA, Donovan TE, Vallittu PK, Närhi TO, Lassila LV. The effect of staining and vacuum sintering on optical and mechanical properties of partially and fully stabilized monolithic zirconia. Dent Mater J 2015;34:605-10.

11. Gresnigt MM, Özcan M, van den Houten ML, Schipper L, Cune MS. Fracture strength, failure type and Weibull characteristics of lithium disilicate and multiphase resin composite endocrowns under axial and lateral forces. Dent Mater 2016;32:607-14.

12. Le Bell-Rönnlöf A-M, Lassila LVJ, Kangasniemi I, Vallittu PK. Load-bearing capacity of human incisors restored wit prefabricated and individually formed fiber reinforced composite posts. Dent Mater 2011;27:107-15.

13. Sedrez-Porto JA, Rosa WL, da Silva AF, Münchow EA, PereiraCenci T. Endocrown restorations: A systematic review and metaanalysis. J Dent 2016;52:8-14.

14. Chang $\mathrm{C}-\mathrm{Y}$, Kuo J-S, Lin $\mathrm{Y}-\mathrm{S}$, Chang $\mathrm{Y}-\mathrm{H}$. Fracture resistance and failure modes of CEREC endo-crowns and conventional post and coresupported CEREC crowns. J Dent Sci 2009;4:110-7.

15. Ozcan M, Valandro LF. Fracture strength of endodontically-treated teeth restored with post and cores and composite cores only. Oper Dent 2009;34:429-36.

16. Carlini-Jr B, Cecchin D, Pereira GD, Paulillo LA. Influence of remaining coronal structure and finish line on the fracture strength of roots restored with metallic posts. Braz Oral Res 2011:25:345-50.

17. Junqueira RB, de Carvalho RF, Marinho CC, Valera MC, Carvalho
CA. Influence of glass fibre post length and remaining dentine thickness on the fracture resistance of root filled teeth. Int Endod J 2017;50:56977.

18. Ceyhanli $K T$, Orucoglu $H$, Erdilek $N$, Turkun $M$, Akdag MS. Microleakage of 4 post-luting cements evaluated by the computerized fluid filtration method. Int J Artif Organs 2015;38:646-50.

19. Sun T, Zhou S, Lai R, Liu R, Ma S, Zhou Z, et al. Load-bearing capacity and the recommended thickness of dental monolithic zirconia single crowns. J Mech Behav Biomed Mater 2014;35:93-101.

20. Waltimo A, Könönen M. Maximal bite force and its association with signs and symptoms of craniomandibular disorders in young Finnish non-patients. Acta Odontol Scand 1995;53:254-8.

21. Nicola S, Forniglia A, Tempesto RM, Comba A, Saratti CM, Pasqualini D, et al. Effects of fiber-glass reinforced composite restorations on fracture resistance and failure mode of endodontically treated molars. J Dent 2016:53;82-7.

22. Fahmy NZ. Effect of dowel material and design on the fracture resistance of premolars. Dentistry 2012:2;116.

\section{Bazı yeni sabitleyici dental sistemler ile desteklenen seramik kronların kırıma yükü}

\section{ÖZET}

AMAÇ: Bu çalışmanın amacı, bilgisayar yardımlı tasarım/ bilgisayar yardımlı imalat (BYT/BYi; CAD/CAM) anterior diş endo-kron ve fiberle güçlendirilmiş kompozit (FGK) esaslı post-kor restorasyonunun kırılma yükünün değerlendirilmesidir.

Gereç Ve Yöntem: CAD/CAM ile kanin kök modeli şeklinde zirkonya model (Ice Zirconia, ZirkonZahn GmBH, Bruneck, Italy) üzerinde toplam 40 post-kor destekli kron ve endokron yapıldı. Statik taşıma yükü kapasitesi değerlendirmesi şu restorasyon gruplarında yapıldı: Grup 1: CAD/ CAM tek parça FGK post-kor-kron sistemi (deneysel CAD/ CAM FGK blok) ile desteklenen zirkonya kron (Prettau anterior, ZirkonZahn GmBH); Grup 2: Devamlı olmayan FGK kor (EverX posterior, GC Corp., Tokyo, Japan) ve FGK post (GC Corp.) ile desteklenen zirkonya kron (Prettau anterior); Grup 3: Zirkonya endokron (Prettau anterior) ve Grup 4: Lityum disilikat seramik endokron (IPS e.max CAD, Ivoclar Vivadent AG, Schaan, Liechtenstein) ( $\mathrm{n}=$ 10/grup). Kronların/endokronların zirkonya kök modele adeziv simantasyonunu takiben, universal test cihazında dişlerin uzun eksenine $45^{\circ}$ olacak şekilde yük uygulandı. Kırık modları görsel olarak değerlendirildi. İstatistiksel analiz tek-yönlü ANOVA ve Tukey post-hoc testleri ile gerçekleştirildi.

BULGULAR: Grupların kırılma yükü değerleri arasında anlamlı farklılık gözlendi $(p<0.05)$. Grupların istatistiksel olarak sıralanması şu şekildedir: Grup $3(1168 \pm 141 \mathrm{~N})>$ Grup $4(721 \pm 96$ N) $\geq$ Grup $1(680 \pm 86 N)>$ Grup $2(534$ $\pm 36 \mathrm{~N})$.

SonuÇ: Endokron monoblok restorasyonlar, fiberle güçlendirilmiş post-kor restorasyon destekli kron restorasyonlara alternatif olarak kullanılabilir.

ANAHTAR KeLimeler: Bilgisayar yardımlı tasarım; bilgisayar yardımlı imalat; kök çivisi tekniği; seramikler 